\title{
Impurity-free amorphous calcium carbonate, a preferential material for pharmaceutical and medical applications
}

\author{
Jonathan Thomas AVARO*, Cristina RUIZ-AGUDO, Eliane LANDWEHR, Karin HAUSER and Denis GEBAUER \\ University of Konstanz, Department of Chemistry, Physical Chemistry, Universitätsstrasse 10, Box 714, \\ 78457 Konstanz, Germany \\ *Corresponding author, e-mail: jonathan.avaro@uni-konstanz.de
}

\begin{abstract}
Biomedical applications of calcium carbonate minerals have been receiving an increasing amount of attention. With a simple chemical composition, low production cost, and ease to produce in large quantities, this non-toxic (bio)mineral has been used preferentially in the pharmaceutical industry as a diluent, bulking or coating agent. Recently, novel products have been developed and amorphous calcium carbonate was successfully used as a hybrid carrier for drugs, proteins and genes. It is obvious that any impurities might have adverse effects in any of the aforementioned applications. However, the synthesis of impurity-free amorphous calcium carbonate often proves to be challenging due to its instability and rapid transformation to crystalline phases. Herein, we describe a novel, simple and scalable protocol for the synthesis of such impurity-free amorphous calcium carbonate nanoparticles that is potentially invaluable for critical health applications, improving the applicability of amorphous calcium carbonates in pharmaceutical and medical domains.
\end{abstract}

Key-words: amorphous calcium carbonate; nanoparticles; impurity-free; synthesis; drug delivery.

\section{Introduction}

The crystallization of $\mathrm{CaCO}_{3}$ has been extensively investigated due to its technological applications and its importance in the formation of biogenic minerals. Calcium carbonate is a model system in which intermediate precursor phases such as pre-nucleation clusters, liquid and solid amorphous precursor phases were shown to occur prior to crystalline phases (Gebauer et al., 2008; Kellermeier et al., 2016; Sebastiani et al., 2017). Among these precursor phases, amorphous calcium carbonate (ACC) plays a pivotal role as an intermediate in the formation of crystalline calcium carbonate polymorphs (Politi et al., 2004; Weiner et al., 2005; Cartwright et al., 2012). Consequently, ACC has drawn a great deal of attention over the last decades resulting in many studies focussed on its formation, structural characterization, and transformation to different crystalline $\mathrm{CaCO}_{3}$ polymorphs. A wide variety of ACC species with diverse hydration level and/or characteristics of short-range order exists, which seems to play a decisive role on the resulting $\mathrm{CaCO}_{3}$ crystalline phase (Gebauer et al., 2008, 2010; Goodwin et al., 2010; Cartwright et al., 2012; Rez et al., 2014; Schmidt et al., 2014; Malini et al., 2016; Sun et al., 2016; Tobler et al., 2016). In the natural environment, species forming biominerals have exploited the tuneable features of amorphous phases and used them as un-differentiated material that will later undergo transformation and specialisation, ultimately forming their shells, teeth or skeleton (Addadi et al., 2003).
Because amorphous precursors can be modified and easily produced at industrial scales, amorphous calcium carbonate mineral phases, possessing intrinsic degradability at acidic $\mathrm{pH}$ values, are promising materials that can be used in many domains such as medicine, e.g., as novel cancer drug delivery systems, for the removal of heavy and toxic metal ions from water, or in materials science for the design of advanced hybrid and nano-composite materials possessing novel physical and optical properties (Cai et al., 2010; Meiron et al., 2011; Lee et al., 2012; Xue et al., 2012; Forsgren et al., 2013; Gebauer, 2013; Qi et al., 2014a and b; Farhadi-Khouzani et al., 2015; Tewes et al., 2016; Blue et al., 2017; Schmidt \& Wagermaier, 2017; Wang et al., 2017, 2018; Xiao \& Tang, 2017; Croitoru et al., 2018).

Given this wide range of applications, a need for an easy and reliable precipitation protocol is obvious. Many studies focussed on these issues and several precipitation protocols can be found in the literature using in- or outgassing diffusion methods, direct precipitation by rapid mixing of saturated solutions, hydrolysis of alkyl carbonate in presence of calcium ions, or direct bubbling of calcium chloride or calcium hydroxide solutions with gaseous $\mathrm{CO}_{2}$ (Becker et al., 2003; Loste et al., 2003; Faatz et al., 2004; Günther et al., 2005; Pouget et al., 2009; Bang et al., 2011; Wang \& $\mathrm{Xu}, 2013$; Gebauer et al., 2013; Ihli et al., 2013a and b, 2014; Rodriguez-Navarro et al., 2015; Farhadi-Khouzani et al., 2015, 2016). However, most of the amorphous precipitates obtained with the various protocols reported in the above cited publications are formed from sodium- or 
chloride-based reactants and hence present traces of impurities being incorporated during the crystallisation or quenching process. It has to be noted that the Kitano protocol based on the slow release of carbon dioxide from a saturated solution of calcium bicarbonate allows the preparation of impurity-fee amorphous or crystalline calcium carbonates (Kitano et al., 1962; Wolf et al., 2008); however, the accessible quantities are rather limited. Related protocols were adapted for the production of precipitated calcium carbonate (PCC) on industrial scales, but typically yield micrometre-sized crystalline particles with versatile use in a wide range of plastic and elastomeric applications (Vogel et al., 2012). Hence, a method for the preparation of impurity-free, nanoscale ACCs in large quantities is still missing. From a general point of view, impurities present a potential limitation and a major challenge as they can have pharmacological or toxicological relevance for the human body but also critically impact the quality of drug products. With the current development of calcium carbonate-based drug delivery systems, the necessity for developing impurity-free ACC phases appears to be essential and has the potential to enhance drug performances and bioavailability (Pan et al., 2011; Qi et al., 2014a and b; Tewes et al., 2016; Wang et al., 2017, 2018). Herein, we addressed these issues and present a novel protocol for the preparation of disordered, stable over several days in low humidity environment and several months in acetone, tuneable, chemical impurity-free, hydrated amorphous calcium carbonate possessing a size range of $155 \pm$ $50 \mathrm{~nm}$. The protocol is in principle scalable, allowing gram scale production.

\section{Materials and methods}

\subsection{Materials}

Amorphous calcium carbonate was precipitated by stepwise addition of water enriched in carbon dioxide to a saturated calcium hydroxide solution $\left(\mathrm{K}_{\mathrm{sp}} \mathrm{Ca}(\mathrm{OH})_{2}=5.5 \times 10^{-6}\right.$; Miller \& Witt, 1928). For the preparation of the $\mathrm{CO}_{2^{-}}$ enriched solution, MilliQ water set at $7{ }^{\circ} \mathrm{C}$ was bubbled with $\mathrm{CO}_{2}$ for $30 \mathrm{~min} 50 \mathrm{~mL}$ of calcium hydroxide set at $7{ }^{\circ} \mathrm{C}$ were placed into a plastic beaker and the $\mathrm{pH}$ was monitored with a Metrohm $\mathrm{pH}$ electrode (model 6.0256.100). The $\mathrm{CO}_{2}$-saturated water was added drop-by-drop to the calcium hydroxide solution at a rate of 10 to $12 \mathrm{~mL} \mathrm{~min}^{-1}$ until the $\mathrm{pH}$ dropped from 12.43 ( $\mathrm{pH}$ of the $\mathrm{Ca}(\mathrm{OH})_{2}$ saturated solution) to $\mathrm{pH} 10.00$. The milky solution was poured into a mixture of $75 \%$ acetone and $25 \%$ absolute ethanol (initial calcium hydroxide to acetone/absolute ethanol volume ratio 1:20) contained in a plastic beaker that was afterwards sealed with Parafilm ${ }^{\mathrm{TM}}$ and stirred with a magnetic stirrer for $3 \mathrm{~min}$. The solution was afterwards left to settle for half an hour after removing the magnetic stirrer. The sedimented amorphous calcium carbonates were then transferred into a falcon tube and centrifuged at $9000 \mathrm{r} / \mathrm{min}$ for $10 \mathrm{~min}$ in a benchtop centrifuge. The supernatant solution was carefully removed, the ACC nanoparticles re-suspended in acetone and centrifuged again. Half of the precipitated total particle weight was stored in acetone and the other half dried under dynamic vacuum conditions at $40{ }^{\circ} \mathrm{C}$ for further characterization. Different ratios of acetone and absolute ethanol for quenching were tested and the above-mentioned proportion proved to provide narrow size distribution of amorphous calcium carbonate nanoparticles (Fig. S1 in Supplementary Material linked to this article and freely available at https://pubs.geoscienceword.org/eurjmin). A single synthesis procedure produced $\sim 100 \mathrm{mg}$ of pure amorphous calcium carbonate. Because this synthesis is essentially based on addition rates and volumes of reactants, it is obvious that this protocol can be up-scaled towards gram scales, if not industrial scales, if required.

\subsection{Scanning electron microscopy}

A Zeiss CrossBeam 1540 XB scanning electron microscope (SEM) was used to examine the samples in secondaryelectron imaging mode. An accelerating voltage of $15 \mathrm{kV}$ was used. Because calcium carbonate is not conductive, images quality is highly dependent on the size and morphology of the samples, therefore powders of ACC were sprinkled onto carbon adhesive tapes and coated with a thin layer of gold (approx. $10 \mathrm{~nm}$ ). For elemental characterization, energy dispersive X-ray analysis (EDX) of calcium carbonate deposited on TEM grids was realised on a benchtop SEM (TM3000, Hitachi) at $15 \mathrm{kV}$.

\subsection{Transmission electron microscopy}

Transmission electron microscopy (TEM) images where acquired using an in-column Omega filter microscope Zeiss Libra 120 at $120 \mathrm{kV}$ accelerating voltage, possessing a point resolution of $0.34 \mathrm{~nm}$. Particles were collected for TEM observations by dipping carbon-film-coated copper grids into the ACC/acetone dispersions. Grids were dried in air and immediately analyzed by TEM.

\subsection{Thermogravimetric analysis}

Thermogravimetric analysis was performed on a NETZSCH STA 449 F3 Jupiter equipment under nitrogen atmosphere to limit crystallization of the samples when exposed to atmospheric conditions. Ten milligrams were positioned in the sample holder. The analysis was performed between room temperature and $900{ }^{\circ} \mathrm{C}$ with a heating rate of $10 \mathrm{~K} / \mathrm{min}$. Prior to all measurements, a calibration was performed using the calibration kit available with the instrument. All measurements were baseline corrected by the curves obtained by placing the empty crucible in the sample holder and heating in the same manner as during the actual measurement. For all measurements, the same starting mass of $10 \mathrm{mg}$ was used. A stand-by mode was applied for $15 \mathrm{~min}$ in order to limit temperature fluctuations and accurately establish the initial weight values using the build-in microbalance under dry gas flow. The standard error associated with the apparatus is $\pm 1.5 \mathrm{wt} \%$.

\subsection{FTIR}

ATR-FTIR spectra of the precipitated particles were recorded on a Perkin Elmer spectrometer 100 equipped with 


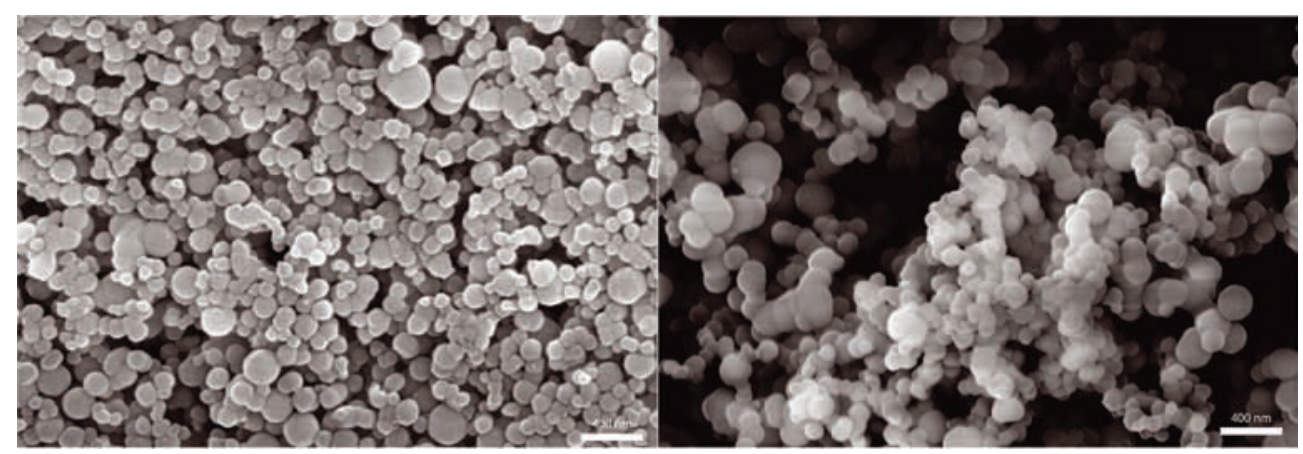

Fig. 1. SEM micrographs of spherical amorphous calcium carbonate nanoparticles. Scale bar $400 \mathrm{~nm}$.

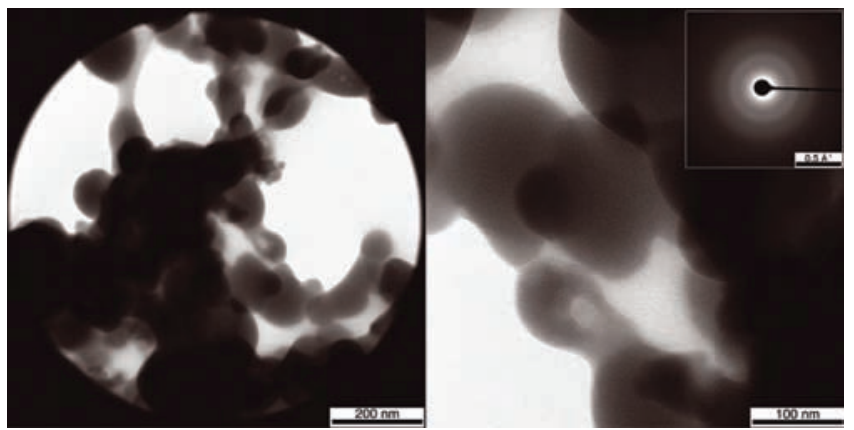

Fig. 2. TEM images of precipitated amorphous calcium carbonate. The SAED pattern in the right inset shows the amorphous character of the particles.

a diamond ATR crystal from 760 to $4000 \mathrm{~cm}^{-1}$ with a resolution of $1 \mathrm{~cm}^{-1}$, allowing the detection of the characteristic calcium carbonate bands denoted $v_{1}, v_{2}, v_{3}$ and $v_{4}$ according to the symmetric stretch, out-of-plane bending, asymmetric stretch and in-plane bending vibrational modes, respectively.

\subsection{Heat treatment of amorphous calcium carbonate}

Amorphous calcium carbonate was placed on a tube oven under $\mathrm{N}_{2}$ flow and heated up to $150{ }^{\circ} \mathrm{C}$ and $250{ }^{\circ} \mathrm{C}$ at a heating rate of $10 \mathrm{~K} / \mathrm{min}$ into a Nabertherm oven equipped with a P320 controller, collected after cooling down and measured via ATR-FTIR. The FTIR scans were normalised based on the intensity of the $v_{3}$ band allowing direct comparison of FTIR spectra.

\section{Results and discussion}

The SEM, EDX and TEM analysis of the dried precipitates show spherical and amorphous $\mathrm{CaCO}_{3}$ particles. An estimation of the size distribution was performed by measuring the size of 120 spherical particles over five different SEM micrographs. The size distribution shows an average value of $155 \pm 50 \mathrm{~nm}$ (Figs. 1-3). The diffuse rings in the selected-area electron diffraction (SAED) pattern confirm that the particles are truly amorphous. Within the limits of SEM and TEM techniques, no traces of crystalline calcium carbonate forms were seen. The EDX elemental analyses (Fig. 4) were realised on the same samples used for TEM analysis, confirming the presence of $\mathrm{C}, \mathrm{O}, \mathrm{Ca}(\mathrm{Al}$ is present due to the SEM sample holder and $\mathrm{Cu}$ due to the TEM grid).

Characteristic infrared bands of carbonate are reported in the literature, the $v_{1}$ band corresponding to the symmetric stretching, the $v_{2}$ band to the out-of-plane bending, the $v_{3}$ band to the anti-symmetric stretching and the $v_{4}$ band to the in-plane bending vibrational modes. Such vibrational bands occur for the precipitated ACC samples between 1065 and $1075 \mathrm{~cm}^{-1}$ for the $v_{1}$ band, at $860 \mathrm{~cm}^{-1}$ for the $v_{2}$ band, between 1065 and $1075 \mathrm{~cm}^{-1}$ for the $v_{3}$ band and a broad band at $\sim 700 \mathrm{~cm}^{-1}$ accounting for $v_{4}$ (Fig. 5). The last band is significantly broader in ACC than in crystalline polymorphs due to the superposition of the carbonate vibrational mode $v_{4}$ with a broad feature due to the hindered rotation of water molecules (Freda et al., 2005). The $v_{4}$ band is extremely sensitive to the absence of medium- to long-range order as typically found in amorphous calcium carbonates (Brečević \& Nielsen, 1989; Loste et al., 2003; Günther et al., 2005; Gueta et al., 2007). Traces of structural water are observed at $\sim 3300 \mathrm{~cm}^{-1}, 1640 \mathrm{~cm}^{-1}$ and $\sim 700 \mathrm{~cm}^{-1}$ (Fig. 6) corresponding to O-H stretching modes, $\mathrm{HOH}$ bending mode and hindered rotation of water molecules, respectively (Addadi et al., 2003; Gebauer et al., 2010; Farhadi-Khouzani et al., 2015). Quantitative discrimination between structural and absorbed water based only on band analysis is difficult, thus thermogravimetric analysis (TGA) was performed.

The TGA (Fig. 7) shows that the precipitated amorphous calcium carbonate contains approximately $1 \mathrm{~mol}$ of $\mathrm{H}_{2} \mathrm{O}$ per mol of $\mathrm{CaCO}_{3}$, which can be subdivided into $65 \%$ weakly and $35 \%$ strongly bound populations, as evident from the two steps of weight-loss between $30^{\circ} \mathrm{C}$ and $350{ }^{\circ} \mathrm{C}$ (Radha et al., 2010; Bushuev et al., 2015; Jensen et al., 2018). The analysis of the mass ratio upon decomposition of anhydrous calcium carbonate into calcium oxide and calcium carbonate follows:

$$
\mathrm{CaCO}_{3} \rightarrow \mathrm{CaO}+\mathrm{CO}_{2} \uparrow(100 \mathrm{u} \rightarrow 56 \mathrm{u}+44 \mathrm{u} \uparrow) .
$$

Analysis of the residual mass from calcium carbonate decomposition into calcium oxide and gaseous carbon indicates that the analysed samples present statistically no impu- 


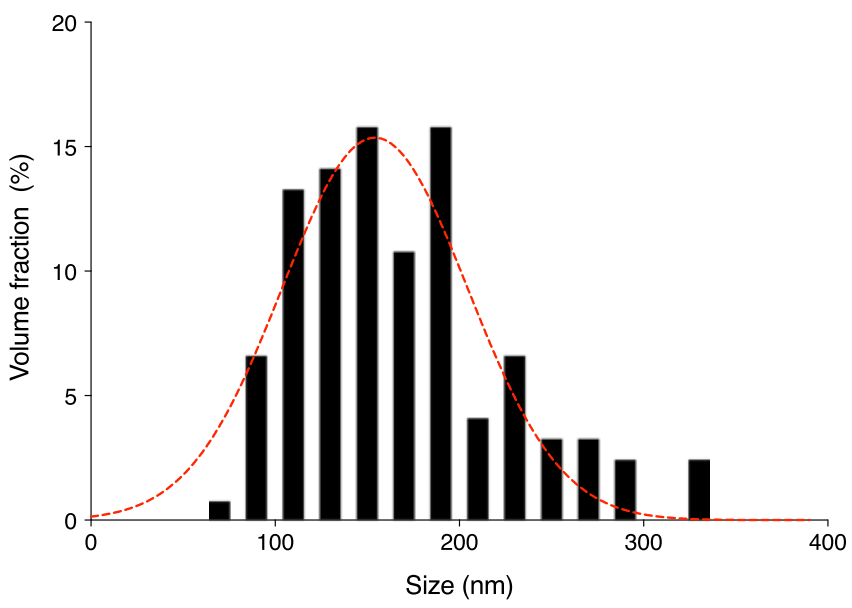

Fig. 3. Size distribution of spherical amorphous calcium carbonate nanoparticles quenched at $\mathrm{pH} 10$ in $75 \%$ acetone and $25 \%$ absolute ethanol. Red curve: Gaussian fit with a mean \pm standard deviation of $155 \pm 50 \mathrm{~nm}$.

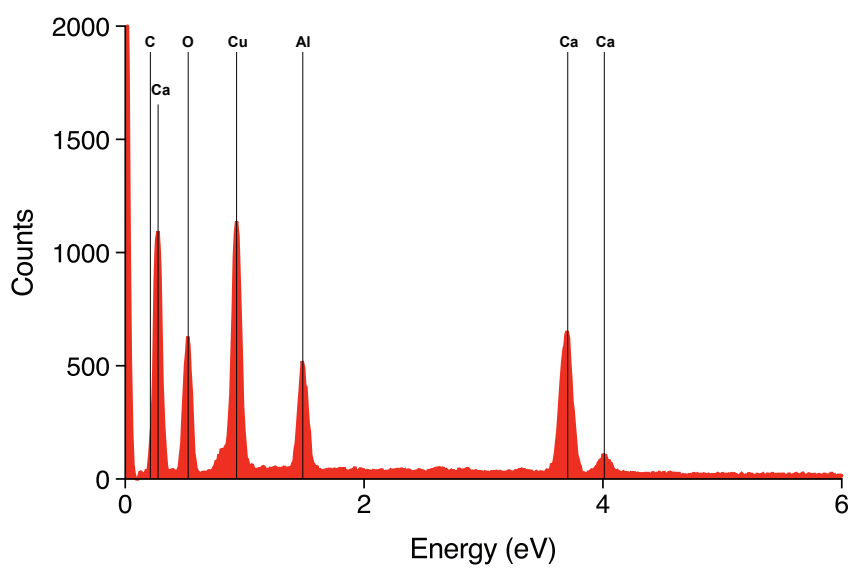

Fig. 4. EDX analysis of ACC deposited onto a TEM grid.

rities (outside of the potential one present in calcium hydroxide reactants). Consequently, the samples are initially composed of $100 \%$ hydrated calcium carbonate of the form $\mathrm{CaCO}_{3}-\mathrm{H}_{2} \mathrm{O}$, which is consistent with the EDX analysis presented above (Fig. 4).

The dehydration capacity of the impurity-free ACC before crystallisation was tested by heating a few milligrams up to $150{ }^{\circ} \mathrm{C}$ and $250{ }^{\circ} \mathrm{C}$. The FTIR spectra were normalised to the $v_{3}$ band intensities. Estimation of the water content upon dehydration was done by a systematic estimation of the water band intensity at $3300 \mathrm{~cm}^{-1}\left(v_{\mathrm{aq}}\right)$ at the different temperatures. Dehydration is expressed in percentages and compared with the maximum intensity of the $v_{\mathrm{aq}}$ band of freshly prepared ACC at room temperature (Figs. 5 and 6). Samples heated to $150{ }^{\circ} \mathrm{C}$ lost about $78 \%$ of their structural water and present no traces of crystals as apparent from the slight shift of the $v_{2}$ vibration band from 862 to $860 \mathrm{~cm}^{-1}$. Changes of the $v_{4}$ vibration band upon heating similarly reflect the change of hydrated water with the appearance and sharpening of the $v_{4}$ double band at 699 and $730 \mathrm{~cm}^{-1}$. A further

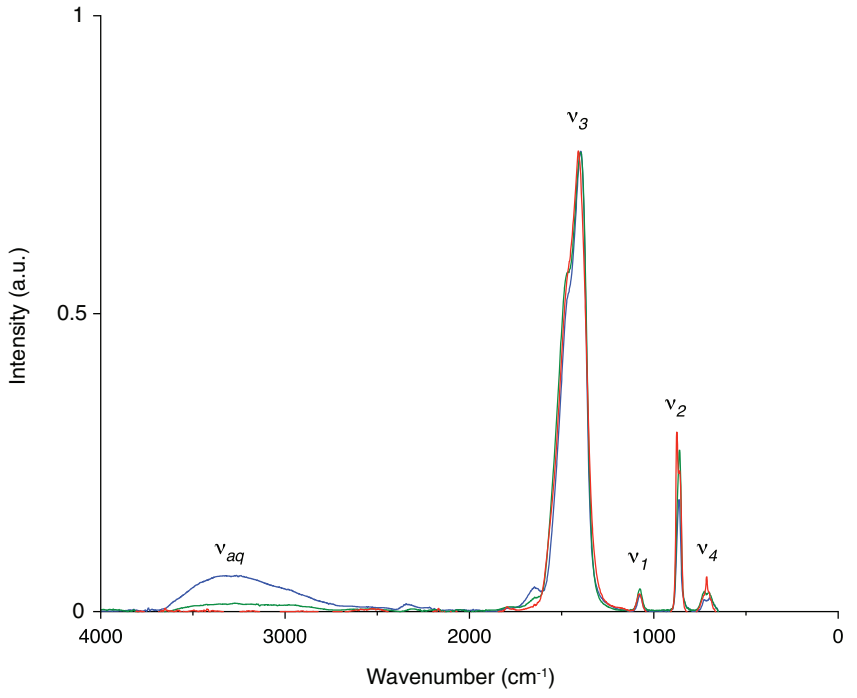

Fig. 5. FTIR analysis of the products of amorphous calcium carbonate after heating. Blue - freshly prepared ACC. Green $-150^{\circ}$ C. Red $-250{ }^{\circ} \mathrm{C}$.

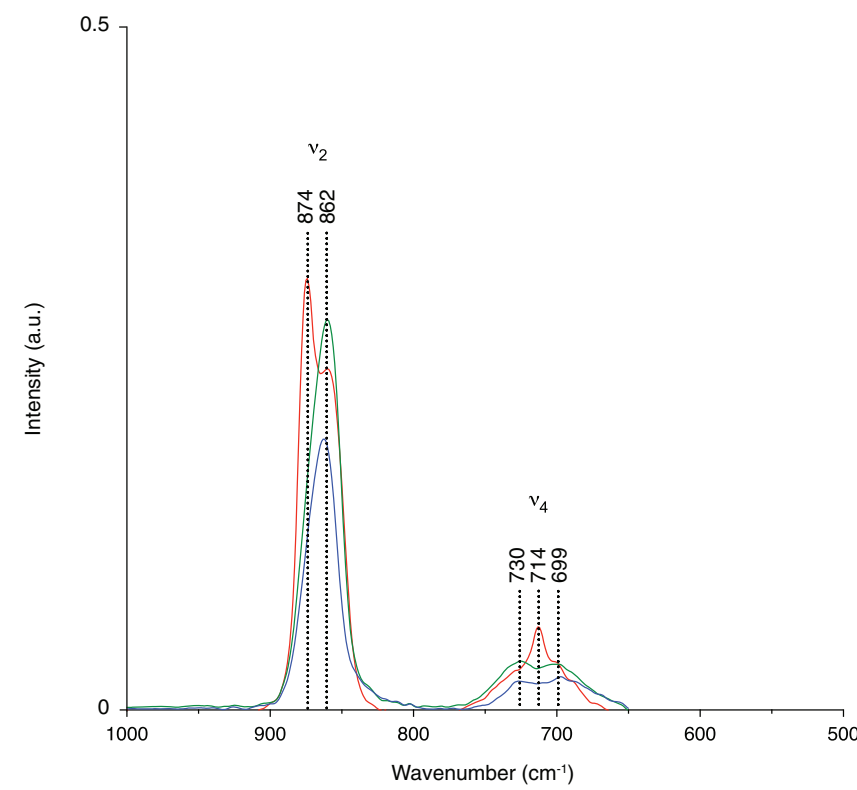

Fig. 6. Enlarged spectral region of $v_{2}$ and $v_{4}$ vibration bands for the samples obtained before and after heat treatment. Crystallisation of the sample can be seen after heating to $250{ }^{\circ} \mathrm{C}$. The characteristic $v_{2}$ vibrational band at $862 \mathrm{~cm}^{-1}$ for ACC shifts to $874 \mathrm{~cm}^{-1}$ for calcite, and the broad $v_{4}$ double band at 699 and $730 \mathrm{~cm}^{-1}$ for ACC sharpens to $714 \mathrm{~cm}^{-1}$ for calcite.

increase in temperature, up to $250{ }^{\circ} \mathrm{C}$, removed all structural water, weakly and strongly bound, but induced a partial crystallisation of ACC into calcite (Fig. 5).

\section{Conclusions}

The presented protocol has proven to produce high yield impurity-free amorphous calcium carbonate via cautious mixing of calcium hydroxide and carbon dioxide-enriched 


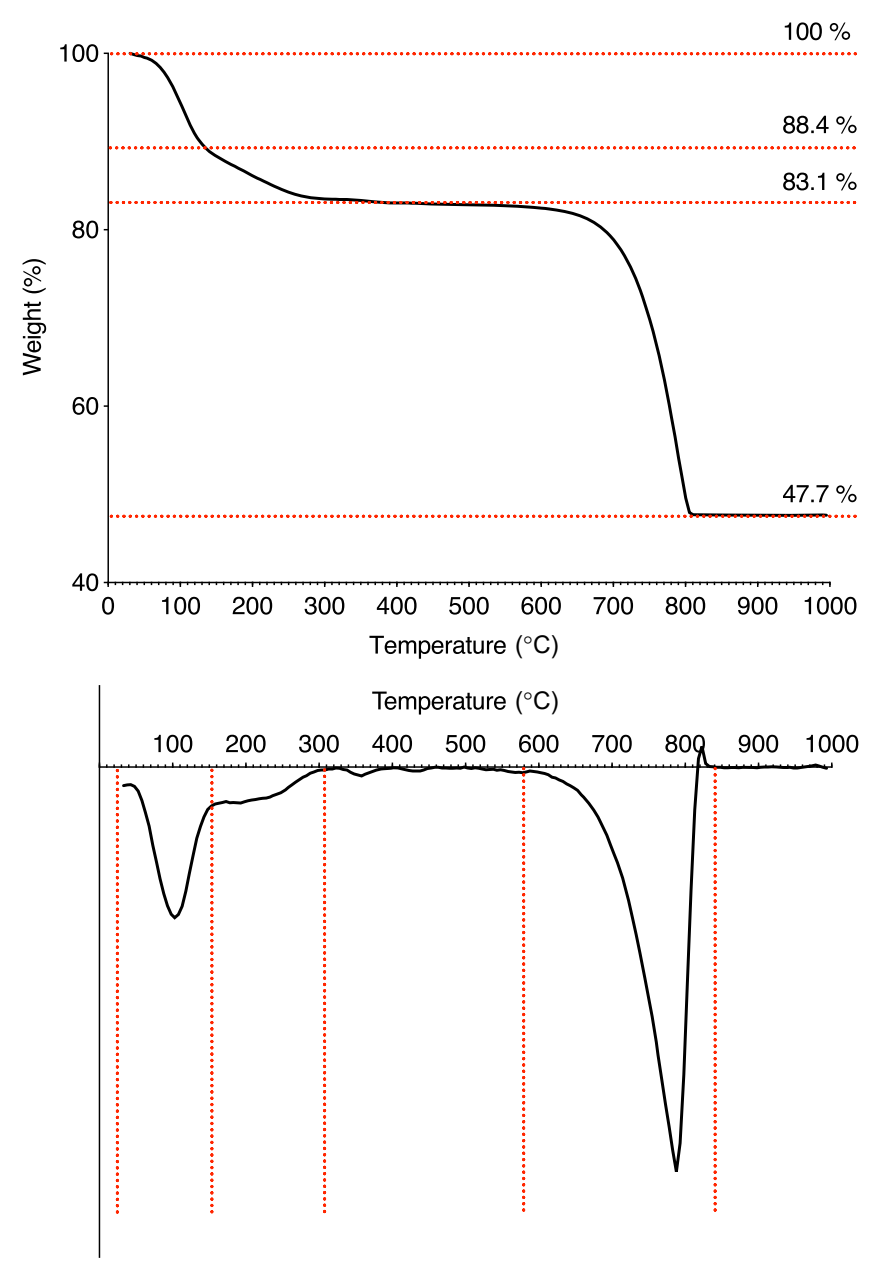

Fig. 7. Top panel - Thermogravimetric analysis of amorphous calcium carbonate precipitated at $\mathrm{pH} 10$ and quenched in $75 \%$ acetone and $25 \%$ absolute ethanol. Bottom panel - First derivative of thermogravimetric analysis used for the determination of the different plateaus.

water. The presented alternative mineralisation pathway intrinsically prevents the incorporation of chemical impurities such as sodium and chloride ions, which are often observed in ACC, because they are not present as spectator ions. Essentially, the purity of the obtained ACC is thus governed by the quality of the used chemicals (calcium hydroxide, water, and organic solvents). Different water contents were tuneable upon heating up to $150{ }^{\circ} \mathrm{C}$ without significant changes towards crystalline structures. Based on the increasing number of publications using ACCs in hybrid materials in various fields, such as industry, medicine, or materials science, this protocol, optimised towards purity, can be upscaled and may allow the development of enhanced synthetic ACC materials for future applications in e.g., hybrid drugs or drug delivery with improved bioavailability.

Acknowledgements: The authors thank the Deutsche Forschungsgemeinschaft (SFB1214, A2 and A7) and the Zukunftskolleg of the University of Konstanz for support.

\section{References}

Addadi, L., Raz, S., Weiner, S. (2003): Taking advantage of disorder: Amorphous calcium carbonate and its roles in biomineralization. Adv. Mater., 15, 959-970.

Bang, J.H., Jang, Y.N., Kim, W., Song, K.S., Jeon, C.W., Chae, S. C., Lee, S.W., Park, S.J., Lee, M.G. (2011): Precipitation of calcium carbonate by carbon dioxide microbubbles. Chem. Eng. J., 174, 413-420.

Becker, A., Bismayer, U., Epple, M., Fabritius, H., Hasse, B., Shi, J., Ziegler, A. (2003): Structural characterisation of X-ray amorphous calcium carbonate (ACC) in sternal deposits of the crustacea Porcellio scaber. Dalt. Trans., 551-555.

Blue, C.R., Giuffre, A., Mergelsberg, S., Han, N., De Yoreo, J.J., Dove, P.M. (2017): Chemical and physical controls on the transformation of amorphous calcium carbonate into crystalline $\mathrm{CaCO}_{3}$ polymorphs. Geochim. Cosmochim. Acta., 196, 179196.

Brečević, L. \& Nielsen, A.E. (1989): Solubility of amorphous calcium carbonate. J. Cryst. Growth, 98, 504-510.

Bushuev, Y.G., Finney, A.R., Rodger, P.M. (2015): Stability and structure of hydrated amorphous calcium carbonate. Cryst. Growth Des., 15, 5269-5279.

Cai, G.B., Zhao, G.X., Wang, X.K., Yu, S.H. (2010): Synthesis of polyacrylic acid stabilized amorphous calcium carbonate nanoparticles and their application for removal of toxic heavy metal ions in water. J. Phys. Chem. C, 114, 12948-12954.

Cartwright, J.H.E., Checa, A.G., Gale, J.D., Gebauer, D., SainzDíaz, C.I. (2012): Calcium carbonate polyamorphism and its role in biomineralization: How many amorphous calcium carbonates are there? Angew. Chemie - Int. Ed., 11960-11970.

Croitoru, C., Spirchez, C., Cristea, D., Lunguleasa, A., Pop, M.A., Bedo, T., Roata, I.C., Luca, M.A. (2018): Calcium carbonate and wood reinforced hybrid PVC composites. J. Appl. Polym. Sci., 135, 46317-46328.

Faatz, M., Gröhn, F., Wegner, G. (2004): Amorphous calcium carbonate: Synthesis and potential intermediate in biomineralization. Adv. Mater., 16, 996-1000.

Farhadi-Khouzani, M., Chevrier, D.M., Güttlein, P., Hauser, K., Zhang, P., Hedin, N., Gebauer, D. (2015): Disordered amorphous calcium carbonate from direct precipitation. CrystEngComm, 17, 4842-4849.

Farhadi-Khouzani, M., Chevrier, D.M., Zhang, P., Hedin, N., Gebauer, D. (2016): Water as the key to proto-aragonite amorphous $\mathrm{CaCO}_{3}$. Angew. Chemie - Int. Ed., 55, 8117-8120.

Forsgren, J., Andersson, M., Nilsson, P., Mihranyan, A. (2013): Mesoporous calcium carbonate as a phase stabilizer of amorphous celecoxib - an approach to increase the bioavailability of poorly soluble pharmaceutical substances. Adv. Healthc. Mater., 2, 1469-1476.

Freda, M., Piluso, A., Santucci, A., Sassi, P. (2005): Transmittance Fourier transform infrared spectra of liquid water in the whole mid-infrared region: Temperature dependence and structural analysis. Appl. Spectrosc., 59, 1155-1159.

Gebauer, D. (2013): Bio-inspired materials science at its bestFlexible mesocrystals of calcite. Angew. Chemie - Int. Ed., 52, 8208-8209.

Gebauer, D., Völkel, A., Coelfen, H. (2008): Stable prenucleation calcium carbonate clusters. Science, 120, 1819-1823.

Gebauer, D., Gunawidjaja, P.N., Ko, J.Y.P., Bacsik, Z., Aziz, B., Liu, L., Hu, Y., Bergström, L., Tai, C.W., Sham, T.K., Edén, M., Hedin, N. (2010): Proto-calcite and proto-vaterite in amorphous calcium carbonates. Angew. Chemie - Int. Ed., 49, 8889-8891.

Gebauer, D., Liu, X., Aziz, B., Hedin, N., Zhao, Z. (2013): Porous tablets of crystalline calcium carbonate via sintering of amorphous nanoparticles. CrystEngComm, 15, 1257-1263. 
Goodwin, A.L., Michel, F.M., Phillips, B.L., Keen, D.A., Dove, M. T., Reeder, R.J. (2010): Nanoporous structure and mediumrange order in synthetic amorphous calcium carbonate. Chem. Mater., 22, 3197-3205.

Gueta, R., Natan, A., Addadi, L., Weiner, S., Refson, K., Kronik, L. (2007): Local atomic order and infrared spectra of biogenic calcite. Angew. Chemie - Int. Ed., 46, 291-294.

Günther, C., Becker, A., Wolf, G., Epple, M. (2005): In vitro synthesis and structural characterization of amorphous calcium carbonate. Z. Anorg. Allg. Chemie, 631, 2830-2835.

Ihli, J., Kim, Y.Y., Noel, E.H., Meldrum, F.C. (2013a): The effect of additives on amorphous calcium carbonate (ACC): Janus behavior in solution and the solid state. Adv. Funct. Mater., 23, 1575-1585.

Ihli, J., Kulak, A.N., Meldrum, F.C. (2013b): Freeze-drying yields stable and pure amorphous calcium carbonate (ACC). Chem. Commun., 49, 3134-3136.

Ihli, J., Wong, W.C., Noel, E.H., Kim, Y.Y., Kulak, A.N., Christenson, H.K., Duer, M.J., Meldrum, F.C. (2014): Dehydration and crystallization of amorphous calcium carbonate in solution and in air. Nat. Commun., 5, 3169.

Jensen, A.C.S., Imberti, S., Parker, S.F., Schneck, E., Politi, Y., Fratzl, P., Bertinetti, L., Habraken, W.J.E.M. (2018): Hydrogen bonding in amorphous calcium carbonate and molecular reorientation induced by dehydration. J. Phys. Chem. C, 122, 35913598.

Kellermeier, M., Raiteri, P., Berg, J.K., Kempter, A., Gale, J.D., Gebauer, D. (2016): Entropy drives calcium carbonate ion association. ChemPhysChem, 17, 3535-3541.

Kitano, Y., Park, K., Hood, D.W. (1962): Pure aragonite synthesis. J. Geophys. Res., 67, 4873-4874.

Lee, K., Wagermaier, W., Masic, A., Kommareddy, K.P., Bennet, M., Manjubala, I., Lee, S.W., Park, S.B., Cölfen, H., Fratzl, P. (2012): Self-assembly of amorphous calcium carbonate microlens arrays. Nat. Commun., 3, 725.

Loste, E., Wilson, R.M., Seshadri, R., Meldrum, F.C. (2003): The role of magnesium in stabilising amorphous calcium carbonate and controlling calcite morphologies. J. Cryst. Growth, 254, 206-218.

Malini, R.I., Bushuev, Y.G., Hall, S.A., Freeman, C.L., Rodger, P. M., Harding, J.H. (2016): Using simulation to understand the structure and properties of amorphous calcium carbonate. CrystEngComm., 18, 92-101.

Meiron, O.E., Bar-David, E., Aflalo, E.D., Shechter, A., Stepensky, D., Berman, A., Sagi, A. (2011): Solubility and bioavailability of stabilized amorphous calcium carbonate. J. Bone Miner. Res., 26, 364-372.

Miller, L.B. \& Witt, J.C. (1928): Solubility of calcium hydroxide. J. Phys. Chem., 33, 285-289.

Pan, C., Liu, F., Motto, M. (2011): Identification of pharmaceutical impurities in formulated dosage forms. Int. J. Drug Dev. Res., 3, 26-33.

Politi, Y., Arad, T., Klein, E., Weiner, S., Addadi, L. (2004): Sea urchin spine calcite forms via a transient amorphous calcium carbonate phase. Science, 306, 1161-1164.

Pouget, E.M., Bomans, P.H.H., Goos, J.A.C.M., Frederik, P.M., De With, G., Sommerdijk, N.A.J.M. (2009): The initial stages of template-controlled $\mathrm{CaCO}_{3}$ formation revealed by Cryo-TEM. Science, 323, 1455-1458.

Qi, C., Zhu, Y.-J., Lu, B.-Q., Zhao, X.-Y., Zhao, J., Chen, F., Wu, J. (2014a): ATP-stabilized amorphous calcium carbonate nanospheres and their application in protein adsorption. Small, 10, 2047-2056.

Qi, C., Zhu, Y.J., Chen, F. (2014b): Microwave hydrothermal transformation of amorphous calcium carbonate nanospheres and application in protein adsorption. ACS Appl. Mater. Interfaces, 6, 4310-4320.
Radha, A.V., Forbes, T.Z., Killian, C.E., Gilbert, P.U.P.A., Navrotsky, A. (2010): Transformation and crystallization energetics of synthetic and biogenic amorphous calcium carbonate. Proc. Natl. Acad. Sci., 107, 16438-16443.

Rez, P., Sinha, S., Gal, A. (2014): Nanocrystallite model for amorphous calcium carbonate. J. Appl. Crystallogr., 47, 16511657.

Rodriguez-Navarro, C., Kudłacz, K., Cizer, Ö., Ruiz-Agudo, E. (2015): Formation of amorphous calcium carbonate and its transformation into mesostructured calcite. CrystEngComm, 17, $58-72$.

Schmidt, I. \& Wagermaier, W. (2017): Tailoring calcium carbonate to serve as optical functional material: Examples from biology and materials science. Adv. Mater. Interfaces, 4, 1600250.

Schmidt, M.P., Ilott, A.J., Phillips, B.L., Reeder, R.J. (2014): Structural changes upon dehydration of amorphous calcium carbonate. Cryst. Growth Des., 14, 938-951.

Sebastiani, F., Wolf, S.L.P., Born, B., Luong, T.Q., Coelfen, H., Gebauer, D., Havenith, M. (2017) Water dynamics from THz spectroscopy reveal the locus of a liquid-liquid binodal limit in aqueous $\mathrm{CaCO}_{3}$ solutions. Angew. Chemie - Int. Ed., 56, 490495.

Sun, S., Chevrier, D.M., Zhang, P., Gebauer, D., Coelfen, H. (2016): Distinct short-range order is inherent to small amorphous calcium carbonate clusters $(<2 \mathrm{~nm})$. Angew. Chemie - Int. Ed., 55, 12206-12209.

Tewes, F., Gobbo, O.L., Ehrhardt, C., Healy, A.M. (2016): Amorphous calcium carbonate based-microparticles for peptide pulmonary delivery. ACS Appl. Mater. Interfaces, 8, 11641175 .

Tobler, D.J., Rodriguez Blanco, J.D., Sørensen, H.O., Stipp, S.L.S., Dideriksen, K. (2016): Effect of $\mathrm{pH}$ on amorphous calcium carbonate structure and transformation. Cryst. Growth Des., 16, 4500-4508.

Vogel, R., Vučak, M., Nover, C., Peitzsch, L. (2012): Precipitated calcium carbonate as carrier particles of 'dry liquids' for postprocessing crosslinking reactions. E-Polymers, 1, 023.

Wang, S.S. \& Xu, A.W. (2013): Amorphous calcium carbonate stabilized by a flexible biomimetic polymer inspired by marine mussels. Cryst. Growth Des., 13, 1937-1942.

Wang, C., Chen, S., Yu, Q., Hu, F., Yuan, H. (2017): Taking advantage of the disadvantage: employing the high aqueous instability of amorphous calcium carbonate to realize burst drug release within cancer cells. J. Mater. Chem. B, 5, 2068-2073.

Wang, C., Chen, S., Wang, Y., Liu, X., Hu, F., Sun J., Yuan, H. (2018): Lipase-triggered water-responsive "Pandora's box" for cancer therapy: Toward induced neighboring effect and enhanced drug penetration. Adv. Mater., 30, 1706407.

Weiner, S., Sagi, I., Addadi, L. (2005): Choosing the crystallization path less traveled. Science, 309, 1027-1028.

Wolf, S.E., Leiterer, J., Kappl, M., Emmerling, F., Tremel, W. (2008): Early homogenous amorphous precursor stages of calcium carbonate and subsequent crystal growth in levitated droplets. J. Am. Chem. Soc., 130, 12342-12347.

Xiao, Y. \& Tang, R.-K. (2017): Nanoparticle drug delivery systems based on biomineralization. Chinese J. Inorg. Chem., 25, 13191327.

Xue, Z., Hu, B., Dai, S., Du, Z. (2012): Crystallization and selfassembly of flowerlike superstructures of calcium carbonate regulated by pepsin Langmuir monolayers. Mater. Chem. Phys., 136, 771-777.

Received 16 May 2018

Modified version received 24 October 2018

Accepted 31 October 2018 